\title{
Preparation of Carbon Nanofiber Supported Platinum and Ruthenium Catalysts: Comparison of Ion Adsorption and Homogeneous Deposition Precipitation
}

\author{
Marjolein L. Toebes, Martijn K. van der Lee, Lai Mei Tang, Marije H. Huis in 't Veld, \\ Johannes H. Bitter, A. Jos van Dillen, and Krijn P. de Jong* \\ Department of Inorganic Chemistry and Catalysis, Debye Institute, Utrecht University, \\ PO Box 80 083, 3508 TB Utrecht, Netherlands
}

Received: December 31, 2003; In Final Form: May 18, 2004

\begin{abstract}
Carbon nanofiber (CNF) supported platinum catalysts have been prepared using $\mathrm{Pt}\left(\mathrm{NH}_{3}\right)_{4}\left(\mathrm{NO}_{3}\right)_{2}$ as a precursor by two different ion adsorption techniques, one at a constant $\mathrm{pH}$ and one in which the $\mathrm{pH}$ is gradually and homogeneously increased from 3 to 6 by hydrolysis of urea. The latter method resembles the procedure of homogeneous deposition precipitation (HDP). Characterization of the CNF support was performed by acidbase titration, thermogravimetric mass spectrometry, and X-ray photoelectron spectroscopy, and for the various platinum catalysts, transmission electron microscopy, $\mathrm{H}_{2}$-chemisorption, and $\mathrm{X}$-ray fluorescence/inductively coupled plasma-atomic emission spectrometry were utilized. With both synthesis techniques from diluted precursor solutions homogeneously distributed, highly dispersed and thermally stable metal particles were obtained with an average particle size of 1-2 nm. With the HDP method for the Pt/CNF catalysts, a linear relationship between the number of acidic oxygen-containing groups on the surface of activated CNF and the metal loading has been found. For the highest loaded catalyst, a platinum/adsorption site ratio of 0.5 was established, corresponding to about $0.7 \mathrm{Pt}\left(\mathrm{NH}_{3}\right)_{4}{ }^{2+}$ molecules $/ \mathrm{nm}^{2}$. Furthermore, it has been established that with this procedure higher platinum loadings $(\sim 4 \mathrm{wt} \%)$ can be achieved than with the ion adsorption procedure $\left(<2\right.$ wt \%). The HDP method using $\mathrm{RuNO}\left(\mathrm{NO}_{3}\right)_{3}\left(\mathrm{H}_{2} \mathrm{O}\right)_{2}$ also turned out to be suitable for the preparation of small $(1-2 \mathrm{~nm})$ uniform ruthenium particles on CNF with a high thermostability.
\end{abstract}

\section{Introduction}

Supported noble metal catalysts often are prepared via aqueous routes, mainly ion adsorption. The term ion adsorption is used to describe processes where ionic species interact electrostatically with charged sites on the support surface. ${ }^{1}$ It is still uncertain which step in the preparation procedure is chiefly responsible for the ultimate size and distribution of the metal particles, but the distribution of the precursor of the active component as accomplished in the adsorption step to a large extent determines the final result. The maximum metal loading depends, among other factors, on the number and nature of the adsorption sites, the $\mathrm{pH}$ of the solution, the speciation of the precursor, and the presence of competing species that may adsorb on the same sites. ${ }^{2}$ Sometimes, using ion adsorption with porous oxidic support bodies inhomogeneous distributions have been reported, especially with loadings smaller than saturation and fast and strong adsorption of the precursor on the support. ${ }^{2,3}$

Several adsorption mechanisms can be found in the literature. Regalbuto et al. ${ }^{4}$ have extensively studied the adsorption of chloroplatinic acid onto alumina and developed the revised physical adsorption (RPA) model. This model implies that in the adsorption process only physical interactions are involved and is therefore also referred to as the formation of outer-sphere complexes. The precursor ions are adsorbed on the surface according to a Langmuir adsorption model with a maximum coverage of a closed packed layer of adsorbate species, retaining one or several hydration shells. With some minor revisions to

* To whom correspondence may be addressed: Tel: +31-30-2536762. Fax: +31-30-2511027. E-mail: k.p.dejong@chem.uu.nl. account for the more complex chemistry of the carbon surface, the RPA model can also be applied to carbon supports. ${ }^{5}$

Another way of considering interaction between precursor species and the surface involves ion adsorption. An electrostatic interaction of adsorbed complexes with the surface can bring about an adsorption of the original ligands by surface ligands. The resulting inner-sphere complexes are chemically bonded to the surface. . $^{6,7}$

For the production of highly loaded and highly dispersed metal/oxide catalysts, the homogeneous deposition precipitation technique (HDP) has been developed. ${ }^{8-10}$ In HDP, the active phase or its precursor is deposited onto an existing support by slowly and homogeneously introducing the precipitating agent in such a way that nucleation in the solution itself is avoided. Factually, this process of "surface precipitation" can be considered as a process in which next to the adsorption stage nucleation of a precursor compound occurs. These nuclei gradually grow, and high loadings can be attained. To avoid nucleation in the bulk of the solution, locally high degrees of super saturation must be prevented. Generally, hydrolysis of urea, added to the suspension of the support, is used to effectuate a slow and homogeneous increase of the hydroxyl concentration. From extensive research on the mechanism of HDP of nickel on silica supports, it was found that during HDP surface compounds such as 1:1 Ni-phyllosilicates are formed. ${ }^{8,9,11,12}$ This procedure has been used with success to produce numerous highly loaded, thermally stable, and highly dispersed catalysts. It is striking that even with graphitelike carbon nanofibers (CNF) as the support, which are unable to form a mixed surface compound, highly loaded catalysts with relatively small metal particles can be obtained. ${ }^{13}$ 
TABLE 1: Sample Codes, Preparation Conditions, and Metal Content Determined by XRF of the Various CNF-Supported Catalysts Determined after Reduction at $473 \mathrm{~K}$

\begin{tabular}{|c|c|c|c|c|c|c|}
\hline sample name & $\mathrm{CNF}$ treatment & metal precursor & $\begin{array}{l}\text { intake } \\
\text { (wt \%) }\end{array}$ & $\begin{array}{c}\text { metal } \\
(\mathrm{wt} \%)^{a}\end{array}$ & $\begin{array}{l}\text { preparation } \\
\text { method }^{b}\end{array}$ & $\begin{array}{l}\text { heat treatment } \\
\text { in } \mathrm{N}_{2}\end{array}$ \\
\hline $\mathrm{RuCNFCl}$ & $\mathrm{KOH}, 2 \mathrm{~h} \mathrm{HNO}_{3}$ & $\mathrm{RuCl}_{3} \cdot n \mathrm{H}_{2} \mathrm{O}$ & 5.0 & n.d. & HDP & \\
\hline RuCNF & $\mathrm{KOH}, 2 \mathrm{~h} \mathrm{HNO}_{3}$ & $\mathrm{RuNO}\left(\mathrm{NO}_{3}\right)_{3} \cdot n \mathrm{H}_{2} \mathrm{O}$ & 5.0 & 5.0 & HDP & \\
\hline RuCNF573 & $\mathrm{KOH}, 2 \mathrm{~h} \mathrm{HNO}_{3}$ & $\mathrm{RuNO}\left(\mathrm{NO}_{3}\right)_{3} \cdot n \mathrm{H}_{2} \mathrm{O}$ & 5.0 & 5.0 & HDP & $573 \mathrm{~K}$ \\
\hline RuCNF773 & $\mathrm{KOH}, 2 \mathrm{~h} \mathrm{\textrm {HNO } _ { 3 }}$ & $\mathrm{RuNO}\left(\mathrm{NO}_{3}\right)_{3} \cdot n \mathrm{H}_{2} \mathrm{O}$ & 5.0 & 5.0 & HDP & $773 \mathrm{~K}$ \\
\hline RuCNF973 & $\mathrm{KOH}, 2 \mathrm{~h} \mathrm{HNO}_{3}$ & $\mathrm{RuNO}\left(\mathrm{NO}_{3}\right)_{3} \cdot n \mathrm{H}_{2} \mathrm{O}$ & 5.0 & 5.0 & HDP & $973 \mathrm{~K}$ \\
\hline PtCNF & $\mathrm{KOH}, 2 \mathrm{~h} \mathrm{HNO}_{3}$ & $\mathrm{Pt}\left(\mathrm{NH}_{3}\right)_{4}\left(\mathrm{NO}_{3}\right)_{2}$ & 5.0 & 3.9 & HDP & \\
\hline PtCNF573 & $\mathrm{KOH}, 2 \mathrm{~h} \mathrm{HNO}_{3}$ & $\mathrm{Pt}\left(\mathrm{NH}_{3}\right)_{4}\left(\mathrm{NO}_{3}\right)_{2}$ & 5.0 & 3.9 & HDP & $573 \mathrm{~K}$ \\
\hline PtCNF773 & $\mathrm{KOH}, 2 \mathrm{~h} \mathrm{HNO}_{3}$ & $\mathrm{Pt}\left(\mathrm{NH}_{3}\right)_{4}\left(\mathrm{NO}_{3}\right)_{2}$ & 5.0 & 3.9 & HDP & $773 \mathrm{~K}$ \\
\hline PtCNF973 & $\mathrm{KOH}, 2 \mathrm{~h} \mathrm{HNO}_{3}$ & $\mathrm{Pt}\left(\mathrm{NH}_{3}\right)_{4}\left(\mathrm{NO}_{3}\right)_{2}$ & 5.0 & 3.9 & HDP & $973 \mathrm{~K}$ \\
\hline PtCNF-A & $\mathrm{KOH}, 0.5 \mathrm{~h} \mathrm{HNO}_{3}$ & $\mathrm{Pt}\left(\mathrm{NH}_{3}\right)_{4}\left(\mathrm{NO}_{3}\right)_{2}$ & 5.0 & 2.7 & HDP & \\
\hline PtCNF-B & $\mathrm{KOH}, 1 \mathrm{~h} \mathrm{HNO}_{3}$ & $\mathrm{Pt}\left(\mathrm{NH}_{3}\right)_{4}\left(\mathrm{NO}_{3}\right)_{2}$ & 5.0 & 3.6 & HDP & \\
\hline PtCNF-C & $\mathrm{KOH}, 1 \mathrm{~h} \mathrm{HCl}$ & $\mathrm{Pt}\left(\mathrm{NH}_{3}\right)_{4}\left(\mathrm{NO}_{3}\right)_{2}$ & 5.0 & 0.0 & HDP & \\
\hline PtCNF-D & $\mathrm{KOH}, 2 \mathrm{~h} \mathrm{HNO}_{3}, \mathrm{~N}_{2} 973 \mathrm{~K}$ & $\mathrm{Pt}\left(\mathrm{NH}_{3}\right)_{4}\left(\mathrm{NO}_{3}\right)_{2}$ & 5.0 & 0.5 & HDP & \\
\hline PtCNF-10 & $\mathrm{KOH}, 2 \mathrm{~h} \mathrm{HNO}_{3}$ & $\mathrm{Pt}\left(\mathrm{NH}_{3}\right)_{4}\left(\mathrm{NO}_{3}\right)_{2}$ & 10.0 & 4.8 & HDP & \\
\hline PtCNF IA-293 & $\mathrm{KOH}, 2 \mathrm{~h} \mathrm{HNO}_{3}$ & $\mathrm{Pt}\left(\mathrm{NH}_{3}\right)_{4}\left(\mathrm{NO}_{3}\right)_{2}$ & 5.0 & 1.4 & IA-293K & \\
\hline PtCNF IA-363 & $\mathrm{KOH}, 2 \mathrm{~h} \mathrm{\textrm {HNO } _ { 3 }}$ & $\mathrm{Pt}\left(\mathrm{NH}_{3}\right)_{4}\left(\mathrm{NO}_{3}\right)_{2}$ & 5.0 & 1.8 & IA-363K & \\
\hline PtCNF IA-pH= 6 & $\mathrm{KOH}, 2 \mathrm{~h} \mathrm{HNO}_{3}$ & $\mathrm{Pt}\left(\mathrm{NH}_{3}\right)_{4}\left(\mathrm{NO}_{3}\right)_{2}$ & 5.0 & 1.1 & IA-293-pH=6 & \\
\hline PtCNF IA-pH $=3-6$ & $\mathrm{KOH}, 2 \mathrm{~h} \mathrm{HNO}_{3}$ & $\mathrm{Pt}\left(\mathrm{NH}_{3}\right)_{4}\left(\mathrm{NO}_{3}\right)_{2}$ & 5.0 & 2.2 & IA-293-pH=3-6 & \\
\hline
\end{tabular}

${ }^{a}$ Reproducibility $= \pm 15 \% .{ }^{b} \mathrm{HDP}=$ homogeneous deposition precipitation; IA $=$ ion adsorption.

Nevertheless, the chemical inertness of graphitelike CNF brings along considerable difficulties in the application of the (precursor of the) active phase via wet chemical routes. ${ }^{14}$ Because of the hydrophobic character of "as synthesized" CNF, their wettability is poor and interaction with dissolved polar precursor species is low. To tackle this problem, the hydrophilic nature of the fibers can be raised by surface oxidation. Pretreatment of CNF with oxidizing agents, e.g., nitric acid, results in the formation of polar oxygen-containing surface groups, which can be acidic, neutral, or basic in nature. ${ }^{15-18}$ Because of the dissociation of carboxyl groups, the point of zero charge (pzc) is decreased from a $\mathrm{pH}$ of $\sim 5$ of the untreated fibers to a $\mathrm{pH}$ of $\sim 2-3 .{ }^{19-22}$ Introduction of these groups increases the ion adsorption capacity too, which is important in view of the attainable loadings with precursor species.

The evolution of surface charge as a function of the $\mathrm{pH}$ is important in view of the loading process using both HDP and ion adsorption. In this respect, oxidic surfaces behave strikingly different from (activated) carbon surfaces. According to Brunelle, ${ }^{23}$ the charge of, e.g., a silica surface (pzc $\approx 2$ ) remains close to zero from $\mathrm{pH} 1$ to $\mathrm{pH} 7$ and only becomes substantial above $\mathrm{pH}$ 7. With carbon supports, the $\zeta$ potential as a function of the $\mathrm{pH}$ develops rather differently. ${ }^{21,23}$ From a $\mathrm{pH}$ value of $2-3$, charging of the surface rapidly increases, but at a $\mathrm{pH}$ of around 5 , a constant level is reached, indicating that all the available adsorption sites have dissociated. This difference is related to the difference in the nature of the adsorption sites, i.e., carboxylic groups for carbon and hydroxyl groups for oxides.

Although many studies in the literature can be found dealing with platinum deposited on carbon (among others), ${ }^{24-28}$ fundamental research on the preparation of carbon-supported platinum catalysts is rather scarce..$^{5,29-35}$ In our research on the application of platinum on $\mathrm{CNF}$, we have compared the results obtained with an HDP method with those obtained with ion adsorption (IA), and we have investigated the extent of interaction between the dissolved metal precursor and the CNF support. To gain more insight in the relation between the ultimate metal loading, particle size distribution, thermal stability, and the number of adsorption sites, we prepared CNF support samples with different numbers of oxygen-containing groups and studied the results obtained with the loading procedures. Additionally, we prepared CNF-supported ruthenium catalysts according to the HDP method.

\section{Experimental Section}

CNF Growth. For the growth of CNF, a 20 wt $\% \mathrm{Ni} / \mathrm{SiO}_{2}$ catalyst was prepared by HDP as described by van Dillen et al. ${ }^{8}$ using silica (Degussa, Aerosil 200), nickel nitrate (Acros), and urea (Acros). After filtering, the catalyst precursor was dried at $393 \mathrm{~K}$ and calcined in static air at $873 \mathrm{~K}$ (heating rate 5 $\mathrm{K} / \mathrm{min}$ ) for $2 \mathrm{~h}$.

Prior to the fiber growth, $1 \mathrm{~g}$ of Ni-catalyst precursor, placed in a quartz-fixed bed reactor, was reduced in situ for $2 \mathrm{~h}$ in a flow of a mixture of $\mathrm{H}_{2}(80 \mathrm{~mL} / \mathrm{min})$ and $\mathrm{N}_{2}(320 \mathrm{~mL} / \mathrm{min})$ at 1 bar and $973 \mathrm{~K}$ (heating rate $5 \mathrm{~K} / \mathrm{min}$ ). Next, the $\mathrm{CNF}$ were grown at $823 \mathrm{~K}$ in a mixture of $\mathrm{CO}(80 \mathrm{~mL} / \mathrm{min}), \mathrm{H}_{2}(28 \mathrm{~mL} /$ $\mathrm{min})$, and $\operatorname{Ar}(292 \mathrm{~mL} / \mathrm{min})$ for $24 \mathrm{~h}$. A more detailed description of the growth catalyst and the growth of the CNF can be found elsewhere. $^{36}$

Activation and Pretreatment of CNF. All CNF samples were refluxed for $1 \mathrm{~h}$ in a $1 \mathrm{M} \mathrm{KOH}$ solution in order to remove the silica support. Subsequently, the CNF were refluxed in concentrated nitric acid for removal of non-encapsulated nickel and activation and washed thoroughly with demineralized water. The activation and pretreatment process was varied to study the effect of type and number of oxygen-containing groups at the surface of the CNF during the application of the active phase (Table 1). Some CNF samples were refluxed in $\mathrm{HCl}$ instead of $\mathrm{HNO}_{3}$ to remove non-encapsulated nickel without introduction of oxygen-containing groups. The remaining nickel is encapsulated by graphitic envelopes, which prevent interference in catalysis. CNF were activated in $\mathrm{HNO}_{3}$ for $0.5,1$, and $2 \mathrm{~h}$, resulting in increasing amounts of oxygen groups. Furthermore, CNF were utilized that, after oxidation in $\mathrm{HNO}_{3}$ for $2 \mathrm{~h}$, were treated in $\mathrm{N}_{2}$ at $973 \mathrm{~K}$ to remove (part of) the surface oxides.

Synthesis of CNF-Supported Ruthenium and Platinum Catalysts. Platinum (intake $5 \mathrm{wt} \%$ ) was deposited as follows. A suspension of $1 \mathrm{~g} \mathrm{CNF}$ in $250 \mathrm{~mL}$ of demineralized water was acidified to $\mathrm{pH}=3$ with nitric acid and heated to $363 \mathrm{~K}$ under inert atmosphere. Subsequently, $0.08 \mathrm{~g}$ of urea (Acros) and $0.10 \mathrm{~g}$ of $\mathrm{Pt}\left(\mathrm{NH}_{3}\right)_{4}\left(\mathrm{NO}_{3}\right)_{2}$ (Aldrich) were added under vigorous stirring. The $\mathrm{pH}$ of the slurry was monitored to follow the process. After the $\mathrm{pH}$ had reached a constant value $(6-18$ $\mathrm{h}, \mathrm{pH} \approx 6,363 \mathrm{~K}$ ), the loaded $\mathrm{CNF}$ were filtered and washed thoroughly with demineralized water, dried at $353 \mathrm{~K}$ in a nitrogen flow, and reduced in $\mathrm{H}_{2}$ at $473 \mathrm{~K}$ for $1 \mathrm{~h}$ (heating rate 
$=5 \mathrm{~K} / \mathrm{min}$ ). In addition, a Pt/CNF catalyst with an intended loading of $10 \mathrm{wt} \%$ has been prepared using this procedure.

For reasons of comparison, $\mathrm{Pt} / \mathrm{CNF}$ catalysts were prepared by means of an ion adsorption. $\mathrm{Pt}\left(\mathrm{NH}_{3}\right)_{4}\left(\mathrm{NO}_{3}\right)_{2}(0.10 \mathrm{~g})$ was dissolved in $250 \mathrm{~mL}$ at $293 \mathrm{~K}$ or at $363 \mathrm{~K}$. Then $1.0 \mathrm{~g}$ of activated $\mathrm{CNF}$ was added to the solution under vigorous stirring. The $\mathrm{pH}$ of the solution was adjusted using a diluted ammonia solution in such a way that a $\mathrm{pH}$ of $\sim 6$ was established after the addition of CNF. After $18 \mathrm{~h}$, the suspension was filtered, washed, and finally dried at $353 \mathrm{~K}$. The whole procedure was carried out in $\mathrm{N}_{2}$ atmosphere.

In two separate experiments, the influence of the $\mathrm{pH}$ on the amount of adsorbed platinum was investigated. A suspension of $1.0 \mathrm{~g} \mathrm{CNF}$ in $250 \mathrm{~mL}$ demineralized water was acidified to $\mathrm{pH}=3$ with nitric acid and stirred for $3 \mathrm{~h}$ at $363 \mathrm{~K}$. After cooling to room-temperature, $\mathrm{Pt}\left(\mathrm{NH}_{3}\right)_{4}\left(\mathrm{NO}_{3}\right)_{2}(0.10 \mathrm{~g}$, Aldrich) was added under vigorous stirring and the $\mathrm{pH}$ was adjusted to 6 with ammonia. After $18 \mathrm{~h}$, the sample was filtered, dried, and subsequently reduced at $473 \mathrm{~K}$ (PtCNF-IA, $\mathrm{pH}=3-6$ ). The metal loading was determined by $\mathrm{X}$-ray fluorescence (XRF) as described below. In a second experiment, $250 \mathrm{~mL}$ of demineralized water was acidified to $\mathrm{pH}=3$ at room temperature with nitric acid and subsequently brought to $\mathrm{pH} 6$ with ammonia to keep the ion strength similar to that in the first experiment. Next $1.0 \mathrm{~g}$ of $\mathrm{CNF}$ and $0.10 \mathrm{~g}$ of $\mathrm{Pt}\left(\mathrm{NH}_{3}\right)_{4}\left(\mathrm{NO}_{3}\right)_{2}$ (Aldrich) were added. After stirring for $18 \mathrm{~h}$ at room temperature under a nitrogen atmosphere, the sample was filtered and dried, all in inert atmospheres and subsequently reduced at $473 \mathrm{~K}$ (PtCNF-IA, $\mathrm{pH}=6$ ). The metal loading was determined by $\mathrm{XRF}$ as described below.

Ruthenium (intake $5 \mathrm{wt} \%$ ) was deposited on the fibers as follows. A suspension of $5 \mathrm{~g}$ of oxidized CNF in $250 \mathrm{~mL}$ of demineralized water was acidified to $\mathrm{pH}=0.5$ with nitric acid and heated to $363 \mathrm{~K}$. Subsequently, $1.56 \mathrm{~g}$ of urea (Acros) and $0.82 \mathrm{~g}$ of $\mathrm{RuNO}\left(\mathrm{NO}_{3}\right)_{3}\left(\mathrm{H}_{2} \mathrm{O}\right)_{2} \cdot n \mathrm{H}_{2} \mathrm{O}$ (Acros) or $0.73 \mathrm{~g}$ of $\mathrm{RuCl}_{3}$ (Acros) were added under vigorous stirring. The $\mathrm{pH}$ of the slurry was monitored to follow the process. After the $\mathrm{pH}$ had reached a constant value $(6-18 \mathrm{~h}, \mathrm{pH} \approx 6,363 \mathrm{~K})$, the loaded $\mathrm{CNF}$ were filtered and washed thoroughly with demineralized water, dried at $393 \mathrm{~K}$, and reduced in $\mathrm{H}_{2}$ at $473 \mathrm{~K}$ for $1 \mathrm{~h}$ (heating rate $=5 \mathrm{~K} / \mathrm{min}$ ).

To investigate the thermostability of both the ruthenium and the platinum catalysts, samples of the freshly reduced catalysts were heat treated in an $\mathrm{N}_{2}$ flow for $2 \mathrm{~h}$ at 573, 773, and $973 \mathrm{~K}$. The description of catalyst treatments together with the identification codes are listed in Table 1.

Catalyst and CNF Characterization. The number of acid sites of the differently pretreated CNF were determined with standard acid-base titrations. For this purpose, 20-40 mg of oxidized CNF was stirred with $25 \mathrm{~mL}$ of a solution containing $0.1 \mathrm{M} \mathrm{NaCl}$ and $0.1 \mathrm{mM}$ oxalic acid in demineralized water, acidified to $\mathrm{pH}=3$ with $\mathrm{HCl}$. While stirring, pure nitrogen was bubbled through the slurry and $10 \mathrm{mM} \mathrm{NaOH}$ was added dropwise from a buret until the endpoint $(\mathrm{pH}=7.5)$ had been reached.

The total number of oxygen-containing groups was measured using thermogravimetric analysis on a Netzsch STA-429 thermobalance. The gases evolved were monitored by a Fisons Thermolab quadropole mass spectrometer, through a capillary situated directly above the sample cup. Samples (20-100 mg) were heated in $\operatorname{Ar}(60 \mathrm{~mL} / \mathrm{min})$ at a rate of $5 \mathrm{~K} / \mathrm{min}$ up to 1123 $\mathrm{K}$ and maintained at that temperature for $1 \mathrm{~h}$.

XPS analyses were performed on a Fisons ESCALAB 210IXL and a Vacuum Generators XPS system. Al K $\alpha$ X-ray radiation was utilized, employing an anode current of $20 \mathrm{~mA}$ at 15 and $10 \mathrm{keV}$, respectively. The pass energy of the analyzer was set at $70 \mathrm{eV}$ for the Fisons apparatus and $50 \mathrm{eV}$ for the Vacuum Generators XPS. The fibers were measured without grinding of the CNF skeins.

The various $\mathrm{CNF}$ samples and the CNF-supported ruthenium and platinum catalysts were examined in a Philips CM-200 FEG transmission electron microscopy (TEM) and a Tecnai 20 FEG TEM both operated at $200 \mathrm{kV}$. After suspension in ethanol under ultrasonic vibration, the samples were brought onto a holey carbon film on a copper grid.

TPR measurements were performed with a TPDRO 1100 instrument from Thermo Quest CE Instruments. A sufficient amount of sample $(\sim 0.02 \mathrm{~g})$ was placed in a fixed bed reactor for analysis. A flow containing 5\% hydrogen and 95\% argon (Hoek Loos) was passed downward through the catalyst bed at a rate of $20 \mathrm{~mL} / \mathrm{min}$ (STP). From the dried flow (molsieves), the hydrogen consumption was measured as a function of temperature (heating rate $=10 \mathrm{~K} / \mathrm{min}$ ) using a tungsten thermal conductivity detector.

Textural analysis was performed with $\mathrm{N}_{2}$ physisorption at 77 $\mathrm{K}$, up to a pressure of 1 bar. From the $\mathrm{N}_{2}$ physisorption data, obtained with a Micromeretics ASAP 2400 apparatus, the BET surface area, the total mesopore volume, and the micropore volume were derived. Prior to the physisorption experiments, the samples were evacuated at $473 \mathrm{~K}$ for at least $16 \mathrm{~h}$.

Ruthenium loadings were determined using inductively coupled plasma atomic emission spectrometry (ICP-AES) on a Vista AZ CCD simultaneous inductively coupled plasma atomic emission spectrometer. The platinum loadings were determined by means of XRF on a Philips PW 1480. Before analysis, the $\mathrm{Pt} / \mathrm{CNF}$ samples were pressed into tablets using a methyl methacrylate binder. Besides the platinum loading, also the residual nickel content of the samples after acid treatment was determined. It turned out that already after refluxing CNF in $\mathrm{HNO}_{3}$ for $0.5 \mathrm{~h}$ of the initial amount of $\sim 3 \mathrm{wt} \%$, only $0.5 \mathrm{wt}$ $\%$ was left.

Hydrogen chemisorption measurements were performed using a Micromeritics ASAP 2010C. Before the chemisorption measurements, each sample was dried in a flow of He at $393 \mathrm{~K}$ for $1 \mathrm{~h}$ and reduced in flowing $\mathrm{H}_{2}$ (flow rate $=50 \mathrm{~mL} / \mathrm{min}$ $\mathrm{STP}$ ) at $473 \mathrm{~K}$ for $2 \mathrm{~h}$, heating rate $5 \mathrm{~K} / \mathrm{min}$. After reduction, the catalyst was degassed for $2 \mathrm{~h}$ at $10^{-1} \mathrm{~Pa}$ at the reduction temperature in order to eliminate chemisorbed hydrogen and water. The isotherms were measured at $308 \mathrm{~K}$. The H/M ratios are based on the amounts adsorbed at zero pressure found by extrapolation of the linear part of the isotherm. Calculations are made with the total amount of adsorbed hydrogen. Estimated average particle sizes and dispersions are based on spherical geometry and an adsorption stoichiometry of $\mathrm{H} / \mathrm{M}_{\mathrm{s}}=1$. The average metal particle size, $d(\mathrm{~nm})$, was calculated from

$$
d D=10^{21} \frac{M 6 \rho_{\text {site }}}{\rho_{\text {metal }} N}
$$

where $D$ is the dispersion, $M$ is the atomic weight $(\mathrm{Ru}=101.07$ $\mathrm{g} / \mathrm{mol}, \mathrm{Pt}=195.09 \mathrm{~g} / \mathrm{mol}), \rho_{\text {site }}$ is the ruthenium surface site density (16.3 Ru atoms $/ \mathrm{nm}^{2}, 12.5 \mathrm{Pt}$ atoms $\left./ \mathrm{nm}^{2}\right), \rho_{\text {metal }}$ is the metal density $\left(\mathrm{Ru} 12.3 \mathrm{~g} / \mathrm{cm}^{3}\right.$, Pt $\left.21.45 \mathrm{~g} / \mathrm{cm}^{3}\right)$, and $N$ is the Avogadro constant $\left(6.022 \times 10^{23} \mathrm{~mol}^{-1}\right) \cdot{ }^{37}$

\section{Results and Discussion}

Characterization of the Support. The CNF are of the fishbone type, meaning that the graphene sheets are oriented at 
TABLE 2: Number of Oxygen Atoms $/ \mathrm{nm}^{2}$ on CNF Surface and Specific Surface Area in $\mathrm{m}^{2} / \mathrm{g}$ as a Function of Activation Treatment as Determined with Acid-Base Titration, XPS, and TGA-MS

\begin{tabular}{|c|c|c|c|c|c|c|c|}
\hline \multirow[b]{2}{*}{ CNF treatment } & \multirow[b]{2}{*}{$S_{\text {BET }} \mathrm{m}^{2} / \mathrm{g}$} & \multicolumn{2}{|c|}{ titration } & \multicolumn{2}{|c|}{ XPS } & \multicolumn{2}{|c|}{ TGA-MS } \\
\hline & & acid site $/ \mathrm{nm}^{2}$ & $\mathrm{O}$ atoms $/ \mathrm{nm}^{2}$ & $\mathrm{O} / \mathrm{C}$ atomic ratio & $\mathrm{O}$ atoms $/ \mathrm{nm}^{2}$ & weight loss (\%) & $\mathrm{O}$ atoms $/ \mathrm{nm}^{2}$ \\
\hline $\mathrm{KOH}, 0.5 \mathrm{~h} \mathrm{HNO}_{3}$ & 156 & $1.0 \pm 0.1$ & $2.0 \pm 0.2$ & & & 4.0 & $8.3 \pm 0.6$ \\
\hline $\mathrm{KOH}, 2 \mathrm{~h} \mathrm{HNO}_{3}$ & 186 & $1.4 \pm 0.1$ & $2.8 \pm 0.2$ & 0.069 & $9.6 \pm 1.4$ & 5.7 & $9.8 \pm 0.8$ \\
\hline $\mathrm{KOH}, 2$ h $\mathrm{HNO}_{3}, \mathrm{~N}_{2} 973 \mathrm{~K}$ & 172 & $\sim 0.03 \pm 0.003$ & $\sim 0.06 \pm 0.006$ & 0.017 & $2.3 \pm 0.3$ & 1.8 & $3.0 \pm 0.3$ \\
\hline
\end{tabular}

an angle to the central axis. ${ }^{14}$ After treatment with nitric acid for $2 \mathrm{~h}$, the fibers remain non-microporous and show a surface area of $186 \mathrm{~m}^{2} / \mathrm{g}$. X-ray diffraction and TEM showed that the graphite-like structure of the CNF had not been affected during activation. Scanning electron microscopy (SEM) revealed an average fiber diameter of $25 \mathrm{~nm}$ with a narrow diameter distribution.

The number of acidic oxygen-containing groups on the CNF samples after the various activation treatments as determined with titration as well as XPS and thermogravimetric analysis mass spectrometry (TGA-MS) results are reported in Table 2. As measured by titration, oxidation with concentrated $\mathrm{HNO}_{3}$ for 0.5 and $2.0 \mathrm{~h}$ resulted in 1.0 and 1.4 acid sites $/ \mathrm{nm}^{2}$, respectively, and heat treatment up to $973 \mathrm{~K}$ in removal of almost all acidic oxygen-containing groups. XPS measurements were executed to establish the amount of oxygen in the outer layer $(2-3 \mathrm{~nm})$ of the carbon fibers. Activation of $\mathrm{CNF}$ in $\mathrm{HNO}_{3}$ for $2 \mathrm{~h}$ resulted in an $\mathrm{O} / \mathrm{C}$ ratio of 0.069 , and after treatment at $973 \mathrm{~K}$ an $\mathrm{O} / \mathrm{C}$ ratio of 0.017 remained. The $\mathrm{O} / \mathrm{C}$ atomic ratios can be converted into a number of oxygen atoms $/ \mathrm{nm}^{2}$ using a model of Gijzeman. ${ }^{38}$ These results (Table 2) show that fibers oxidized in $\mathrm{HNO}_{3}$ for $2 \mathrm{~h}$ would expose $9.6 \mathrm{O}$ atoms $/ \mathrm{nm}^{2}$ and $2.3 \mathrm{O}$ atoms $/ \mathrm{nm}^{2}$ after heat treatment. Since oxygen-containing groups contain one or two oxygen atoms, this implies that after activation according to the XPS results about 5-10 oxygencontaining groups would be present per nanometer squared when it is assumed that all oxygen is located at the exterior surface. Values up to $1-3$ groups $/ \mathrm{nm}^{2}$, as earlier proposed by Boehm, seem to be more realistic. ${ }^{17}$ An explanation for this discrepancy could be found in the assumption that oxygen atoms are not exclusively present at the surface but also are built-in in the subsurface $(2-3 \mathrm{~nm})$ graphene sheets. ${ }^{18,39}$ TGA-MS was used to establish the number of thermally removable oxygen atoms from the surface and the bulk of the activated CNF. When all oxygen atoms were considered to be located at the surface, a concentration was found of 8.3 and 9.8 atoms $/ \mathrm{nm}^{2}$ after oxidation in $\mathrm{HNO}_{3}$ for, respectively, 0.5 and $2 \mathrm{~h}$. After treatment at $973 \mathrm{~K}$, this concentration drops to $3.0 \mathrm{O}$ atoms $/ \mathrm{nm}^{2}$. The number of oxygen atoms as determined using XPS and TGAMS is comparable when the error margins are taken into account. From these results and from earlier work, ${ }^{40}$ it is concluded that after treatment at $973 \mathrm{~K}$ oxygen is not present throughout the carbon support but is mainly located in the outer $2-3 \mathrm{~nm}$ of the fibers. These results also show that upon treatment at 973 $\mathrm{K}$ in $\mathrm{N}_{2}$ some very thermostable nonacidic groups remain, whereas acidic groups are hardly detected. For a more detailed investigation on the effects of oxidation of CNF we refer to. ${ }^{40}$

The number of acidic groups found for the CNF treated in $\mathrm{HNO}_{3}$ for $2 \mathrm{~h}$ could give rise to a ruthenium loading of at most $4.2 \mathrm{wt} \%$ using ion adsorption, when it is assumed that the metal precursor species use one site for adsorption and no polymeric ruthenium species are present. With these assumptions for platinum, it should be possible to obtain a loading of maximally 8.2 wt $\%$.

Synthesis and Characterization of the Pt/CNF Catalysts. For the synthesis of CNF-supported platinum catalysts (intake

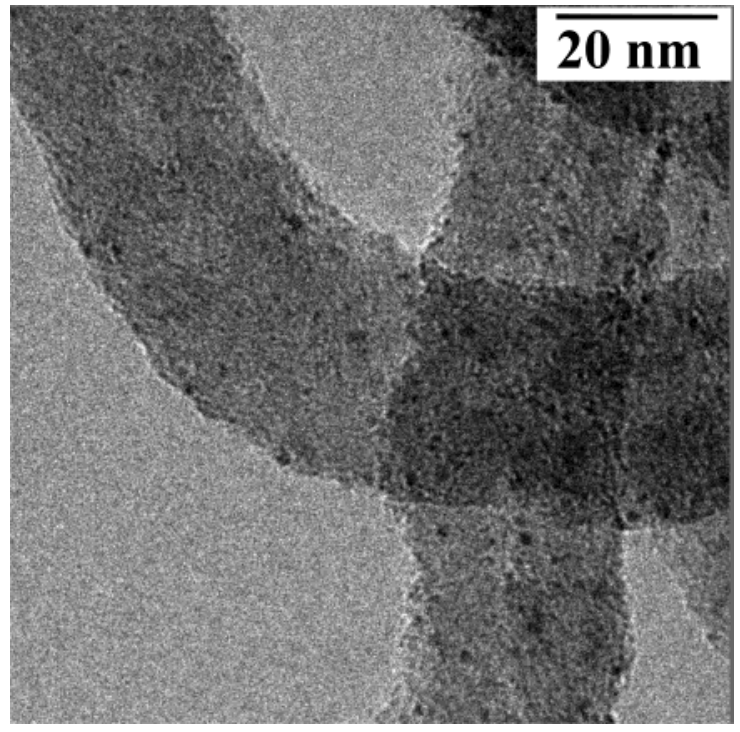

Figure 1. TEM image of PtCNF after reduction at $473 \mathrm{~K}$.

5 wt \%), we started with the HDP method, utilizing $\mathrm{Pt}\left(\mathrm{NH}_{3}\right)_{4}{ }^{-}$ $\left(\mathrm{NO}_{3}\right)_{2}$ as the precursor salt and activated $\mathrm{CNF}\left(2 \mathrm{~h} \mathrm{HNO}_{3}\right)$ (PtCNF). From the TPR results of the dried PtCNF, a reduction temperature of $473 \mathrm{~K}$ of the precursor could be derived. A number of PtCNF catalysts were prepared in this way. The actual metal loading of these catalysts after reduction, determined using both ICP and XRF, turned out to be ca. $3.9 \mathrm{wt} \%$ (Table 1).

In Figure 1, a TEM image of the PtCNF catalyst after drying and reduction at $473 \mathrm{~K}$ is displayed. Platinum particle sizes are in the range $1-2 \mathrm{~nm}$. The dispersion calculated from hydrogen chemisorption is 0.79 , indicating platinum particles with an average size of $1.4 \mathrm{~nm}$.

The final loading of PtCNF was considerably below the intake loading of $5 \mathrm{wt} \%$. By use of the number of acidic oxygen groups available (1.4 groups $\left./ \mathrm{nm}^{2}\right)$, we calculated a loading of $8.2 \mathrm{wt} \%$ based on a one-to-one adsorption, so a loading of 5 wt \% should have been feasible. To verify this result, we also prepared a catalyst via the HDP method with an increased intake platinum loading of $10 \mathrm{wt} \%$ (PtCNF-10). The final platinum loading of PtCNF-10 was found by XRF analysis to be only 4.8 wt \% (Table 1). In Figure 2, a TEM image of PtCNF-10 after reduction at $473 \mathrm{~K}$ is shown. In this catalyst, platinum is well dispersed over the surface of the CNF, particles in the narrow range 1-2 $\mathrm{nm}$ are observed. These results show that with the HDP method using $\operatorname{Pt}\left(\mathrm{NH}_{3}\right)_{4}\left(\mathrm{NO}_{3}\right)_{2}$ as the precursor salt small and homogeneously distributed platinum particles can be obtained. However, the attained metal loading is smaller than the calculated one-to-one adsorption loading for both ion adsorption and the HDP method. This can be due to the low platinum concentrations $\left(\sim 10^{-3} \mathrm{M}\right)$ used throughout this work leading to incomplete adsorption. Another reason for this difference could be found in a platinum/site ratio of 2 . In this case, a platinum loading of $4.1 \mathrm{wt} \%$ as a maximum can be expected, which is close to the loadings found for these catalysts. 


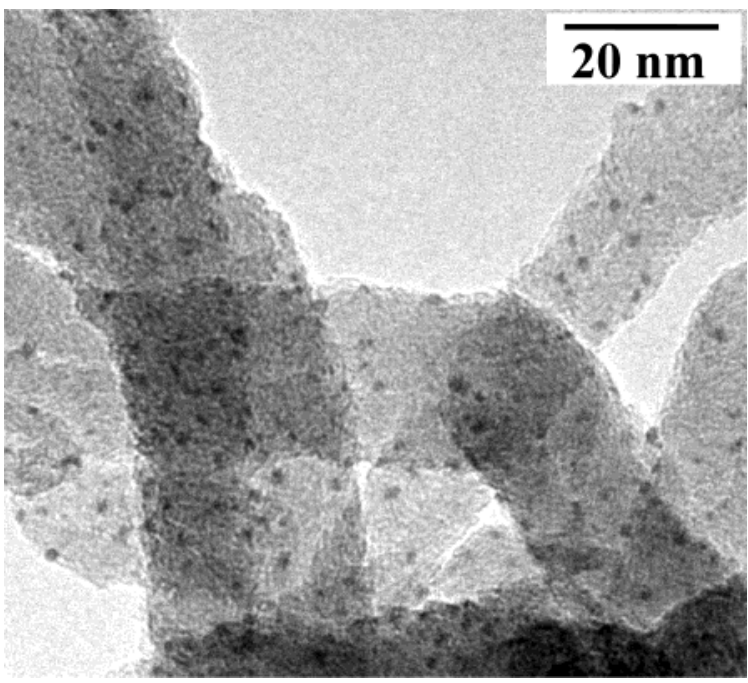

Figure 2. TEM image of PtCNF-10 after reduction at $473 \mathrm{~K}$.

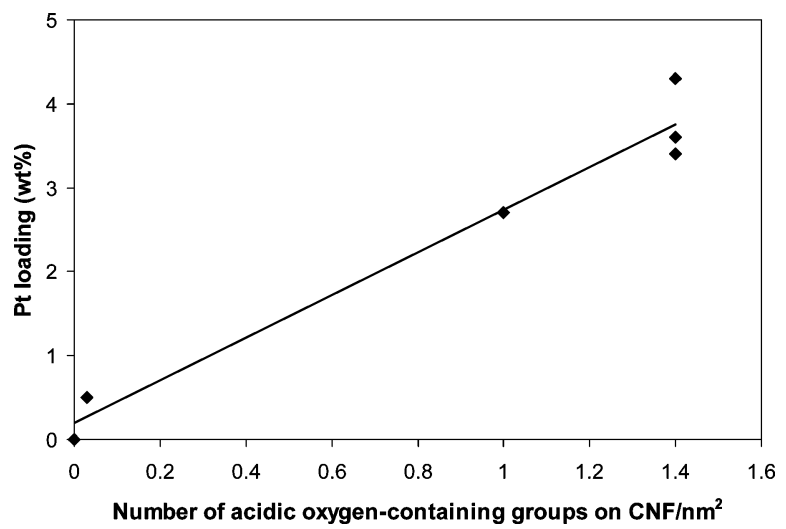

Figure 3. Relationship between number of acidic oxygen-containing surface groups on CNF support and the Pt loading of the catalyst

To gain more insight in the relation between the metal loading and the number of adsorption sites on the support, experiments were performed in which platinum was applied via the HDP method on differently activated and pretreated CNF. We compared the results obtained with this method with the characteristics of CNF-supported platinum catalysts prepared by ion adsorption.

The effect of the number of oxygen-containing groups was investigated through samples PtCNF and PtCNF-A-D. PtCNF is prepared from $\mathrm{CNF}$ oxidized in $\mathrm{HNO}_{3}$ for $2 \mathrm{~h}$, while $\mathrm{CNF}$ in PtCNF-A and -B are only treated for 0.5 and $1 \mathrm{~h}$, respectively. From earlier work and from Table 2, it is known that a shorter oxidation time yields less (acidic) oxygen-containing groups. ${ }^{40}$ The CNF used for the preparation of PtCNF-C are treated in $\mathrm{HCl}$ instead of in $\mathrm{HNO}_{3}$, implying that no surface oxides have been introduced. For the synthesis of PtCNF-D, CNF are applied that are oxidized in $\mathrm{HNO}_{3}$ for $2 \mathrm{~h}$ and are subsequently treated in $\mathrm{N}_{2}$ at $973 \mathrm{~K}$ for $2 \mathrm{~h}$ to remove acidic oxygen-containing groups. The final platinum loadings of the various CNFsupported catalysts were determined with XRF (Table 1).

The effect of the number of acidic oxygen-containing surface groups (oxidation time) on the metal loading can be derived from Table 1. For PtCNF-A and -B, platinum loadings of 2.7 and $3.6 \mathrm{wt} \%$, respectively, were found. PtCNF-C does not contain a significant amount of platinum, and the loading of PtCNF-D is very small $(0.5 \mathrm{wt} \%)$.

In Figure 3, the metal loading is plotted vs the number of acidic oxygen-containing groups on the CNF surface. This figure

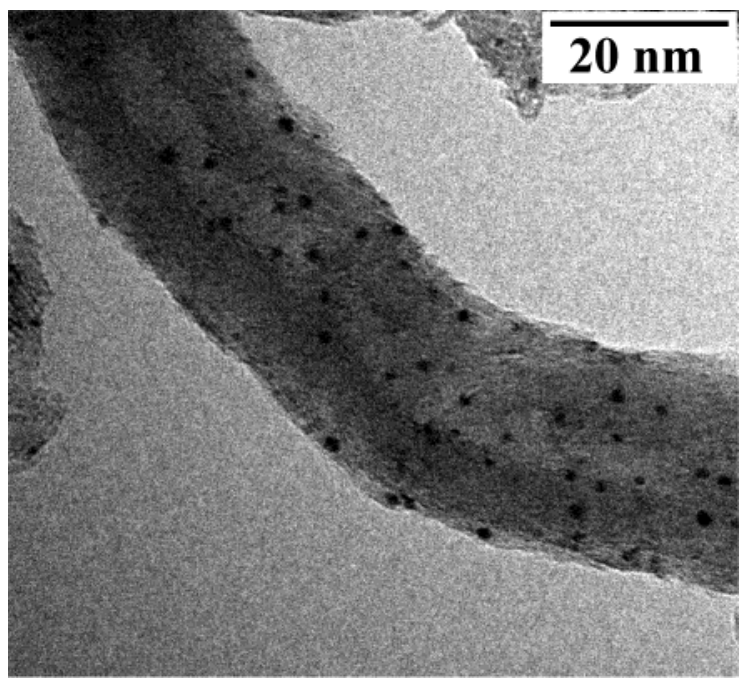

Figure 4. TEM image of PtCNF-B after reduction at $473 \mathrm{~K}$.

shows that as a first approximation a linear correlation exists between the number of acid sites and the amount of platinum that can be deposited on the CNF using the HDP method. Therefore we conclude that the acidic oxygen groups on the CNF surface are not only necessary to increase the wettability using aqueous precursor solutions but also for the anchoring of the metal precursor.

TEM was used to investigate the average platinum particle size and the size distribution on the CNF support. For PtCNF-C and $-\mathrm{D}$, platinum particles could not be detected. TEM images of PtCNF-A (not-shown) and -B (Figure 4) demonstrate that in both catalysts, similar to what we found with PtCNF (Figure $1)$, very small platinum particles $(1-2 \mathrm{~nm})$ are present well distributed over the CNF surface.

A remarkable finding is that HDP and ion adsorption (performed at 293 and $363 \mathrm{~K}$ (PtCNF IA-293/363)) gave different results with respect to the attainable loading. The loadings of these catalysts as determined with XRF analysis can be found in Table 1. The platinum loadings of the catalysts prepared using ion adsorption at 293 and $363 \mathrm{~K}$ are 1.4 and 1.8 wt \% respectively, which is substantially smaller than $3.9 \mathrm{wt}$ $\%$ found for the PtCNF catalysts prepared by the HDP method. This difference in loading we will discuss later on together with the somewhat higher loading of the catalyst prepared by ion adsorption at $363 \mathrm{~K}$. In Figure 5, a TEM image of PtCNF IA293 is shown. From this image, it is clear that the platinum loading is indeed much lower than that of the catalysts prepared via the HDP method. From the TEM images, a particle size distribution of 1-2 nm for PtCNF IA-293 and of 1-4 nm for PtCNF IA-363 was obtained. The average platinum particle sizes calculated from $\mathrm{H}_{2}$-chemisorption are 0.8 and $1.5 \mathrm{~nm}$, respectively.

Synthesis and Characterization of the Ru/CNF Catalysts. We briefly investigated the HDP method for the preparation of CNF-supported ruthenium catalysts. Ruthenium (intake $5 \mathrm{wt} \%$ ) was deposited on the fibers using two ruthenium precursors, viz., $\mathrm{RuCl}_{3}$ and $\mathrm{RuNO}\left(\mathrm{NO}_{3}\right)_{3}\left(\mathrm{H}_{2} \mathrm{O}\right)_{2}$. In the majority of the studies reported in the literature on the preparation of rutheniumsupported catalysts, ruthenium chloride has been utilized as the precursor compound. First, we explored the preparation of CNF-supported ruthenium catalysts using this precursor salt (RuCNFCl). A catalyst with a relatively small average particle size of $3 \mathrm{~nm}$ was obtained, as can be seen in Figure 6A. SEM (not shown) and TEM images of the dried catalyst, however, 


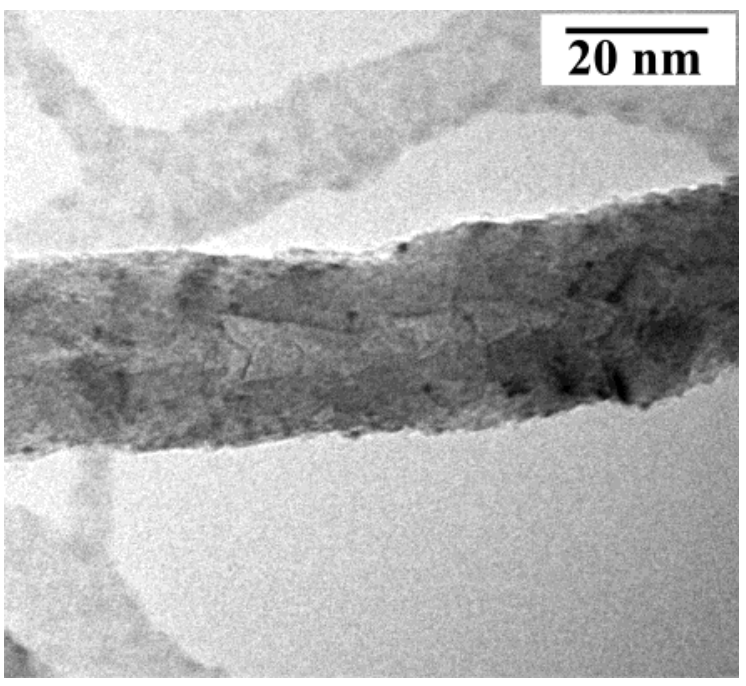

Figure 5. TEM image of PtCNF IA-293 after reduction at $473 \mathrm{~K}$.

revealed the presence of large lumps of ruthenium oxide next to the support (Figure 6B).

Apparently commercial ruthenium chloride is not a suitable precursor, since it may contain, as reported in the literature, ${ }^{41}$ as much as $80 \% \mathrm{Ru}(\mathrm{IV})$, which is only soluble at a very low
$\mathrm{pH}$. We speculate that these $\mathrm{Ru}(\mathrm{VI})$ species precipitate, and $\mathrm{RuO}_{2}$ is formed next to the support, ultimately resulting in the large ruthenium lumps.

Second, $\mathrm{RuNO}\left(\mathrm{NO}_{3}\right)_{3}$ was used as the precursor salt for the synthesis (RuCNF). TPR results showed that the CNF-supported ruthenium precursor was completely reduced at $473 \mathrm{~K}$. Therefore this temperature was chosen as reduction temperature for the $\mathrm{Ru} / \mathrm{CNF}$ catalysts. The metal loading of the $\mathrm{Ru} / \mathrm{CNF}$ catalysts as established with ICP coincides with the intake ruthenium loading of $5 \mathrm{wt} \%$. In Figure 7 two representative TEM images of RuCNF after reduction are shown. The ruthenium particles appear as dark dots on the fiber surface. In Figure 7B, at higher magnification, even the fishbone structure of the CNF is visible. The images show a homogeneous coverage with small ruthenium particles, and no large ruthenium particles were observed. The ruthenium particle size distribution is very narrow; a size range of 1.1-2.2 $\mathrm{nm}$ has been established with an average particle size of $1.5 \mathrm{~nm}$. The metal dispersion calculated from hydrogen chemisorption is 0.74 , corresponding to ruthenium particles with an average size of $1.8 \mathrm{~nm}$. The reproducibility of the HDP procedure using $\operatorname{RuNO}\left(\mathrm{NO}_{3}\right)_{3}$ was checked several times, and always high dispersions and ruthenium particles were found in the $1-2 \mathrm{~nm}$ range.

Thermostability of RuCNF and PtCNF. To examine the stability of the RuCNF and PtCNF catalysts prepared by the
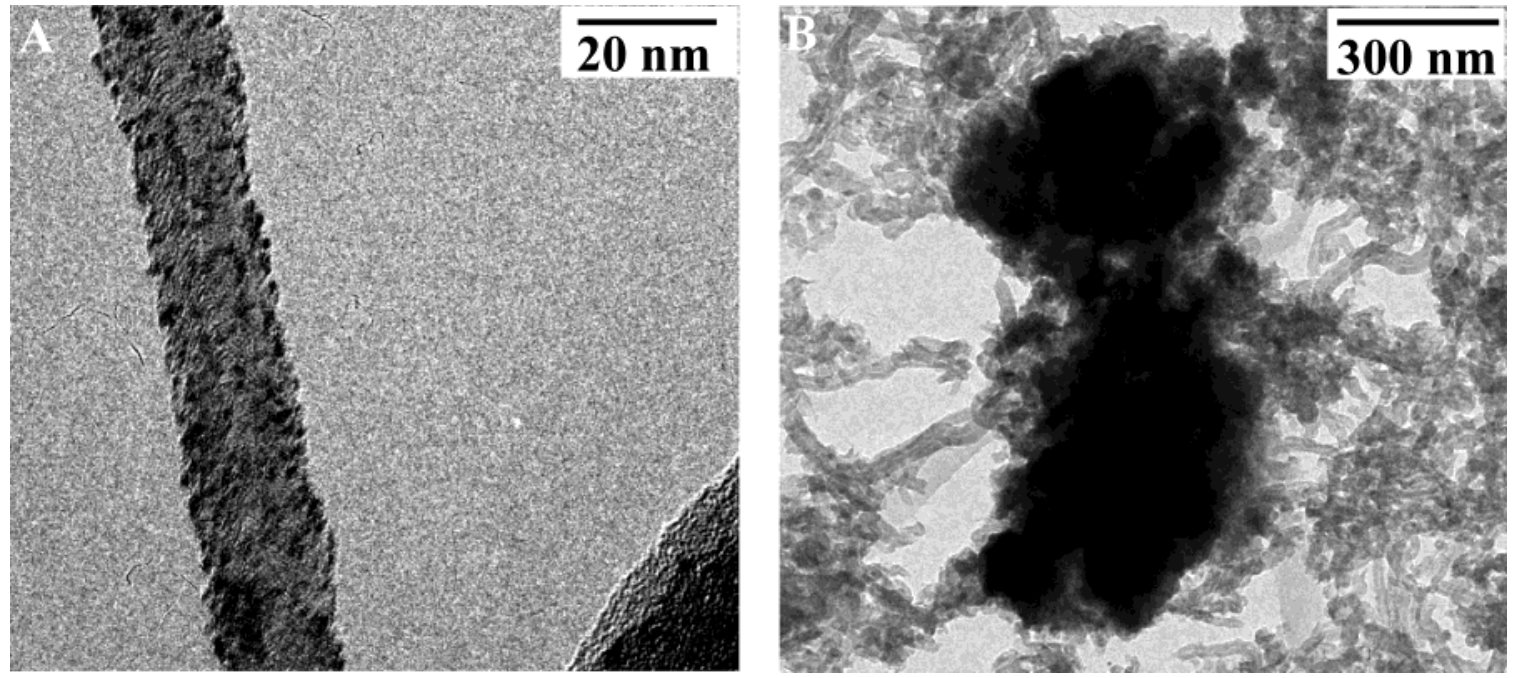

Figure 6. TEM images of dried RuCNFCl (5 wt \%) prepared using HDP and rutheniumchloride.
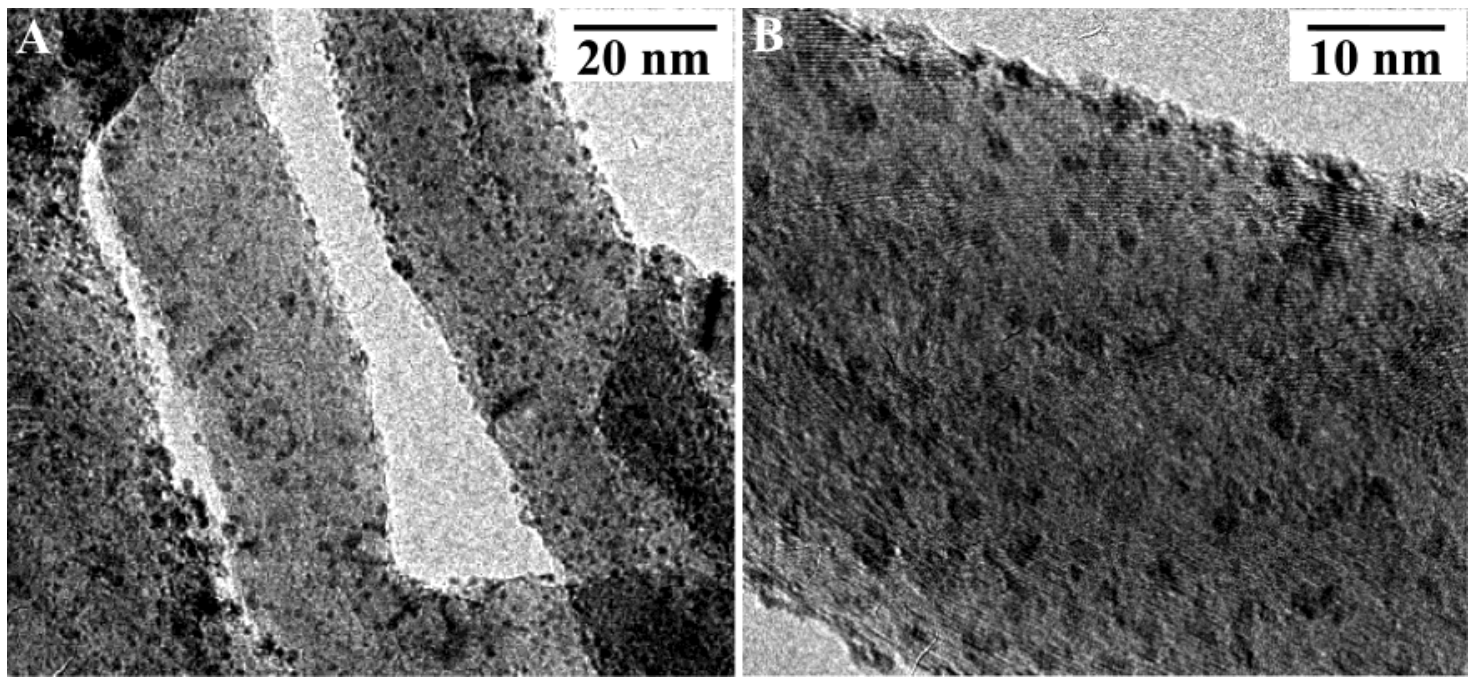

Figure 7. TEM images of RuCNF (5 wt \%) prepared using HDP and rutheniumnitrosylnitrate after reduction at $473 \mathrm{~K}$. 

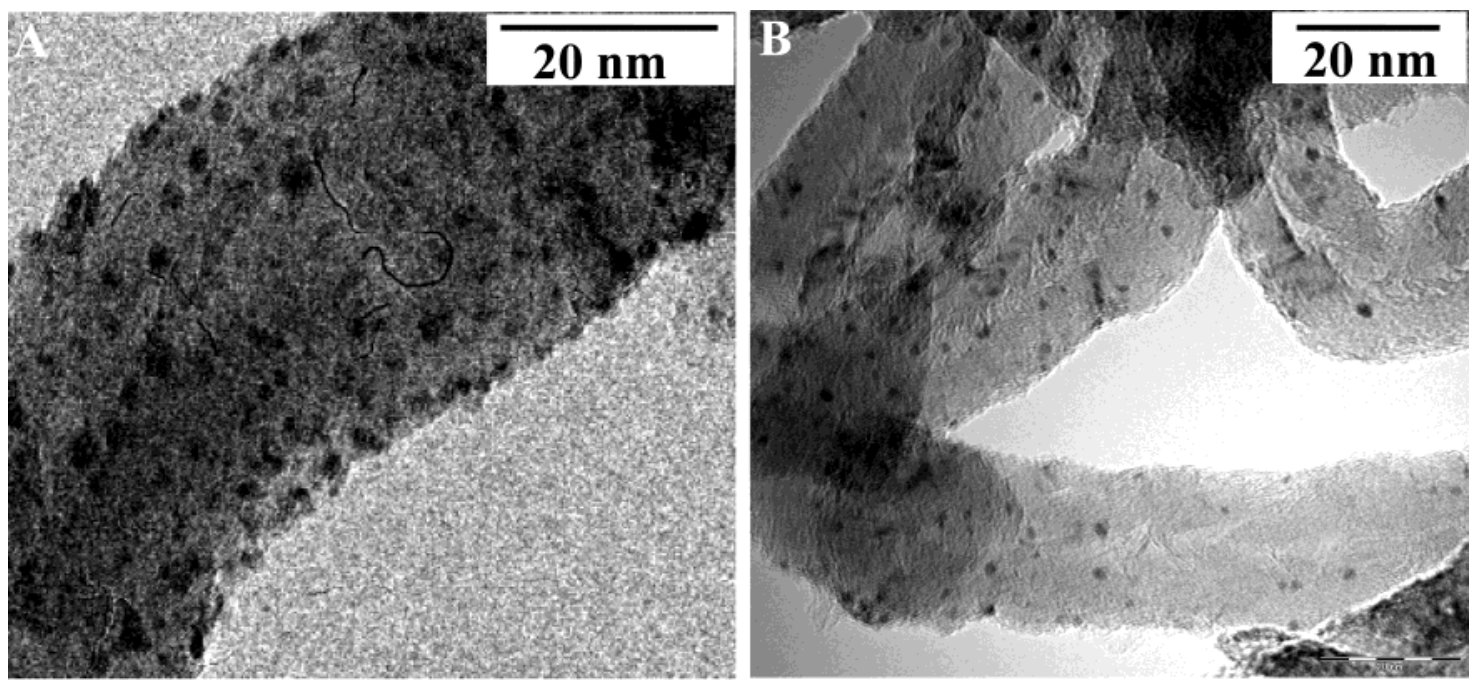

Figure 8. TEM images of (a) RuCNF973 and (b) PtCNF973 after reduction and subsequent heat treatment in $\mathrm{N}_{2}$ at $973 \mathrm{~K}$.

TABLE 3: Dispersions and Average Particles Sizes of Reduced PtCNF and RuCNF Treated at 573, 773, and $973 \mathrm{~K}$ for $2 \mathrm{~h}$ in $\mathbf{N}_{2}$

\begin{tabular}{lccc}
\hline & & \multicolumn{2}{c}{$\mathrm{H}_{2}$ chemisorption } \\
\cline { 3 - 4 } sample & TEM d $(\mathrm{nm})$ & $\mathrm{H}_{\text {total }} / \mathrm{M}$ & $\mathrm{d}(\mathrm{nm})$ \\
\hline PtCNF & $1-2$ & 0.79 & 1.4 \\
PtCNF573 & $1-2$ & 1.06 & 1.1 \\
PtCNF773 & $1-2$ & 0.74 & 1.5 \\
PtCNF973 & $1-3$ & 0.49 & 2.3 \\
RuCNF & $1.5 \pm 0.2$ & 0.74 & 1.8 \\
RuCNF573 & n.d. & 0.70 & 1.9 \\
RuCNF773 & $2.2 \pm 0.6$ & 0.64 & 2.1 \\
RuCNF973 & $1.8 \pm 0.7$ & 0.44 & 3.0
\end{tabular}

HDP method, the catalysts reduced at $473 \mathrm{~K}$ were treated at elevated temperatures in nitrogen. After this treatment, the catalysts were characterized with TEM. In parts a and b of Figure 8, TEM images of RuCNF973 and PtCNF973 are presented. Both the ruthenium and the platinum particle sizes remain (almost) unaltered after treatment up to $773 \mathrm{~K}$. After treatment at $973 \mathrm{~K}$, the particles have become slightly larger; however, still many small particles are present. Some sintering caused broadening of the particle size distribution and a small increase in the average particle size. The dispersions and the average particle sizes calculated from the hydrogen chemisorption data are listed in Table 3. These values are in close agreement with the estimated TEM values. This demonstrates the surprisingly strong bond between the CNF support and the metal particles. In literature, it is well established that when activated CNF are heated in an inert atmosphere, carboxyl and anhydride groups are already decomposed at temperatures beyond $473 \mathrm{~K} .{ }^{17,18,40}$ However, it is important to note that nonacidic oxygen groups still remain. The thermostability of these groups is rather high: decomposition under inert atmosphere starts at ca. $873 \mathrm{~K} .{ }^{17,18,40} \mathrm{We}$ speculate that these groups are key to stabilize the metal particles and prevent their sintering even at a temperature as high as $973 \mathrm{~K}$.

Metal Precursor/Adsorption Site Ratio. The aim of this study was, next to the synthesis of highly dispersed and thermostable platinum and ruthenium on CNF catalysts, to find a relation between metal loading and the number of surface groups on CNF. For both preparation procedures, we succeeded in the first aim. No inhomogeneities, as sometimes reported in the literature for porous oxidic support bodies, ${ }^{2,3}$ were found using ion adsorption. However, we cannot exclude that at higher metal precursor concentrations results of the methods will differ.
We speculate that by use of the HDP method, due to the controlled way of making adsorption sites available, a more homogeneous distribution can be obtained than with ion adsorption.

The relation between the amount of platinum metal that could be deposited and the number of adsorption sites is less unequivocal. That such a relation exists is likely from Figure 3 in which a linear relationship is demonstrated between the number of acidic sites and the platinum loading. What still has to be explained is the difference in loading between the catalysts prepared by ion adsorption and the HDP method. Factors that can influence the ultimate loading are, among others, the number and nature of the adsorption sites, the $\mathrm{pH}$ of the solution, and the concentration and speciation of the metal precursor. These parameters will be discussed below.

In the literature, concentrations of the metal precursor employed for ion adsorption are usually in the range $10^{-1}$ $10^{-3}$ M. ${ }^{29,42-45}$ In our work, rather diluted precursor solutions were utilized, especially for the preparation of the platinum catalysts $\left(\sim 10^{-3} \mathrm{M}\right.$ platinum and $\sim 10^{-2} \mathrm{M}$ ruthenium). When adsorption is reversible, low concentrations as used could have resulted in an incomplete utilization of the adsorption sites. However, this should hold not only for the ion adsorption procedure but also for the HDP method if adsorption is not followed by nucleation and growth.

For PtCNF (3.9 wt \%) and RuCNF (5.0 wt \%) catalysts prepared by the HDP method, the number of metal precursor molecules per square nanometer is 0.7 and 1.6, respectively. According to the revised physical adsorption (RPA) model developed by Regalbuto et al. involving physical interactions, also a maximum platinum loading can be derived. ${ }^{46}$ By use of $\mathrm{Pt}\left(\mathrm{NH}_{3}\right)_{4}{ }^{2+}$, the expected maximum adsorption density would be 0.5 platinum precursor molecules $/ \mathrm{nm}^{2}$ based on a maximum coverage of a closed packed layer of $\mathrm{Pt}\left(\mathrm{NH}_{3}\right)_{4}{ }^{2+}$ ions with two hydration shells. The adsorption density found for PtCNF is, taking into account the roughness of the estimations, in rather good agreement with the value predicted by the RPA model.

We also stated that the speciation of the metal precursor could affect the metal loading. For $\mathrm{Pt}\left(\mathrm{NH}_{3}\right)_{4}{ }^{2+}$, no indication was found in the literature that hydrolysis or polymerization of the precursor can occur, so probably this precursor retains its $2+$ charge irrespective of the $\mathrm{pH}$ and needs as a consequence two neighboring adsorption sites as is often reported for oxidic supports. ${ }^{2,43}$ Although the average active site density on CNF is relatively low, i.e., $\sim 1.4$ sites $/ \mathrm{nm}^{2}$, due to their presumable 
inhomogeneous distribution two-to-one adsorption might be possible. That this two-to-one adsorption is not to be excluded is emphasized by the fact that a Pt/acid site ratio of around 0.5 is found using HDP. Apparently, growth of the nuclei on the support by the formation of platinum hydroxide or some hydroxy compound does not occur, which probably is due to the high stability of the $\mathrm{Pt}\left(\mathrm{NH}_{3}\right)_{4}{ }^{2+}$ complex. Precipitation of platinum hydroxide has never been observed in our experiments, notwithstanding the low solubility product of $\operatorname{Pt}(\mathrm{OH})_{2}\left(\sim 10^{-33}\right.$ $\left.\mathrm{mol}^{3} / \mathrm{l}^{3}\right)$ calculated from the relevant reduction potentials.

On the speciation of $\left[\mathrm{RuNO}\left(\mathrm{NO}_{3}\right)_{3}\left(\mathrm{H}_{2} \mathrm{O}\right)_{2}\right]$, on the other hand, somewhat more information can be found in the literature. Hydrolysis of this precursor in aqueous solutions is reported, resulting in species such as $\left[\mathrm{RuNO}\left(\mathrm{NO}_{3}\right)_{2}\left(\mathrm{H}_{2} \mathrm{O}\right)_{3}\right]^{+}{ }^{4}{ }^{4}$ For $\mathrm{RuCNF}$, a Ru/acid site ratio of ca. 1.2 can be calculated, whose ratio is close to the ratio expected for one-to-one adsorption.

Finally, the differences in initial $\mathrm{pH}$ of the slurry of support and metal salt might be the reason for the deviating platinum loadings achieved with ion adsorption and the HDP procedure. Ion adsorption is up to now performed at constant $\mathrm{pH}(\sim 6)$, while when using the HDP method, the support is exposed to an acidic environment for a long period of time during the procedure. We speculate that due to this treatment more adsorption sites become available, possibly by hydrolysis of carboxylic anhydrides. In the literature, it is shown that during oxidative activation of CNF, carboxyl groups are formed that upon removal of water during drying can be converted into carboxylic anhydride groups. ${ }^{18,31,48-51}$ Hydrolysis of these anhydrides is an activated process; anhydrides are fairly stable, especially around neutral $\mathrm{pH} .{ }^{52-54}$ Since both with titration and with the HDP method a low starting $\mathrm{pH}$ is used, it is possible that in this environment more anhydrides are hydrolyzed to carboxylic groups than occurs with ion adsorption performed at a constant $\mathrm{pH}$ of around 6. This hypothesis is tested by two sorption experiments. In the first one, the Pt complex is adsorbed at room temperature at $\mathrm{pH} 6$ after the support was stirred for 3 $\mathrm{h}$ at $\mathrm{pH} 3$ at $363 \mathrm{~K}(\mathrm{PtCNF} \mathrm{IA}-\mathrm{pH}=3-6$, Table 1$)$. This sample contained $2.2 \mathrm{wt} \%$ of Pt. When the sorption was carried out at room temperature at $\mathrm{pH} 6(\mathrm{PtCNF} \mathrm{IA}-\mathrm{pH}=6$; Table 1$)$, i.e., without bringing the support first to $\mathrm{pH} \mathrm{3}$, a metal loading of $1.1 \mathrm{wt} \%$ was obtained. This supports our proposition that more sorption sites are available after the treatment of the sample at $\mathrm{pH}=3$ as discussed above.

\section{Conclusions}

CNF-supported platinum catalysts were prepared by an HDP method as well as by ion adsorption. By use of diluted precursor solutions with both techniques, small uniform thermally stable platinum particles $(1-2 \mathrm{~nm})$ were obtained homogeneously distributed over the CNF. The HDP method, however, resulted in significantly higher platinum loadings than ion adsorption. This difference could originate from the creation of additional adsorption sites due to the hydrolysis of anhydridic carboxyl groups, formed during drying of the activated CNF, in the acidic environment at which HDP is started. With the HDP method, also CNF-supported ruthenium catalysts were prepared successfully. We consider that the HDP method used for the preparation of CNF-supported platinum catalysts is an ion adsorption procedure, in which in a controlled manner the acid sites slowly become available at increasing $\mathrm{pH}$ during the synthesis resulting in a high dispersion.

For HDP, a linear relationship was found between the number of acidic oxygen groups on the CNF support and the obtained platinum loading. For the highest loaded catalyst, a platinum/ adsorption site ratio of 0.5 was established, corresponding to about $0.7 \mathrm{Pt}\left(\mathrm{NH}_{3}\right)_{4}{ }^{2+}$ molecules $/ \mathrm{nm}^{2}$. It is concluded that the acidic oxygen-containing groups do not only increase the wettability but are also the anchoring sites of the metal precursor during the preparation. We suggest that the nonacidic oxygen groups avoid sintering of the metal particles, resulting in the high thermostability.

Acknowledgment. The authors are grateful to C. van der Spek and J. W. Geus for TEM studies and V. Koot for the $\mathrm{H}_{2}$ chemisorption experiments. These investigations are supported by the Council for Chemical Sciences of The Netherlands Organization for Scientific Research with financial aid from The Netherlands Technology Foundation (CW/STW 349-5357).

\section{References and Notes}

(1) Schlögl, R.; Che, M.; Clause, O.; Marchilly, C. Preparation of Solid Catalysts; Wiley-VCH: Weinhein, 1999; Chapters 3 and 4.

(2) Geus, J. W.; van Veen, J. A. R. Stud. Surf. Sci. Catal. 1999, 123, 459.

(3) Geus, J. W.; Wells, P. B. Appl. Catal. 1985, 18, 231

(4) Spieker, W. A.; Regalbuto, J. R. Chem. Eng. Sci. 2001, 56, 3491

(5) Regalbuto, J. R.; Schrier, M.; Hao, X.; Spieker, W. A.; Kim, J. G.; Miller, J. T.; Kropf, A. J. Stud. Surf. Sci. Catal. 2002, 143, 45.

(6) Lambert, J.-F.; Che, M. J. Mol. Catal. A Chem. 2000, 162, 5.

(7) Lepetit, C.; Che, M. J. Mol. Catal. A Chem. 1995, 100, 147.

(8) van Dillen, A. J.; Geus, J. W.; Hermans, L. A. M.; van der Meijden, J. J. Proc. Int. Congr. Catal. 1977, 2, 677.

(9) Hermans, L. A. M.; Geus, J. W. Stud. Surf. Sci. Catal. 1979, 3, 113.

(10) de Jong, K. P. Stud. Surf. Sci. Catal. 1991, 63, 19.

(11) Burattin, P.; Che, M.; Louis, C. J. Phys. Chem. B 1997, 101, 7060

(12) Burattin, P.; Che, M.; Louis, C. J. Phys. Chem. B 1998, 102, 2722

(13) Bitter, J. H.; van der Lee, M. K.; Slotboom, A. G. T.; van Dillen, A. J.; de Jong, K. P. Catal Lett. 2003, 89, 139.

(14) de Jong, K. P.; Geus, J. W. Catal. Rev. Sci. Eng. 2000, 42, 481

(15) Rodriguez-Reinoso, F. Carbon 1998, 36, 159

(16) Jansen, R. J. J. Ph. D. Thesis, Delft University, 1994

(17) Boehm, H. P. Adv. Catal. 1966, 16, 179.

(18) Ros, T. G.; van Dillen, A. J.; Geus, J. W.; Koningsberger, D. C Chem.-Eur. J. 2002, 8, 1151.

(19) Hoogenraad, M. S. Ph. D. Thesis, Utrecht University, 1995.

(20) Garcia, A. B.; Cuesta, A.; Montes-Moran, M. A.; Martinez-Alonso,

A.; Tascon, J. M. D. J. Colloid Interface Sci. 1997, 192, 363.

(21) Li, Y.-H.; Wang, S,; Luan, Z.; Ding, J.; Xu,.; Wu, D. Carbon 2003 41,1057

(22) Bismarck, A.; Wuertz, C.; Springer, J. Carbon 1999, 37, 1019

(23) Brunelle, J. P. Pure Appl. Chem. 1978, 50, 1211.

(24) Zhou, Z.; Wang, S.; Zhou, W.; Wang, G.; Jiang, L.; Li, W.; Song,

S.; Liu, J.; Sun, G.; Xin, Q. Chem. Commun. 2003, 394.

(25) Yang, B.; Lu, Q.; Wang, Y.; Zhuang, L.; Lu, J.; Liu, P.; Wang, J.; Wang, R. Chem. Mater. 2003, 15, 3552.

(26) Li, W.; Liang, C.; Zhou, W.; Qiu, J.; Zhou, Z.; Sun, G.; Xin, Q. J. Phys. Chem. B 2003, 107, 6292.

(27) Bessel, C. A.; Laubernds, K.; Rodriguez, N. M.; Baker, R. T. K. J. Phys. Chem. B 2001, 105, 1115.

(28) Chen, W. X.; Lee, J. Y.; Liu, Z. Chem. Commun. 2002, 2588.

(29) Fraga, M. A.; Jordão, E.; Mendes, M. J.; Freitas, M. M. A.; Faria, J. L.; Figueiredo, J. L. J. Catal. 2002, 209, 355.

(30) Prado-Burguete, C.; Linares-Solano, A.; Rodriguez-Reinoso, F.; Salinas-Martinez de Lecea, C. J. Catal. 1991, $128,397$.

(31) Aksoylu, A. E.; Madalena, M.; Freitas, A.; Fernando, M.; Pereira R.; Figueiredo, J. L. Carbon 2001, 39, 175.

(32) Fuente, A. M.; Pulgar, G.; Gonzalez, F.; Pesquera, C.; Blanco, C. Appl. Catal. A Gen. 2001, 208, 35.

(33) Okhlopkova, L. B.; Lisitsyn, A. S.; Likholobov, V. A.; Gurrath, M.; Boehm, H. P. Appl. Catal., A 2000, 204, 229.

(34) de Miguel, S. R.; Scelza, O. A.; Roman-Martinez, M. C.; SalinasMartinez de Lecea, C.; Cazorla-Amoros, D.; Linares-Solano, A. Appl. Catal. A Gen. 1998, 170, 93.

(35) Roman-Martonez, M. C.; Cazorla-Amoros, D.; Linares-Solano, A.; Salinas-Martinez-de Lecea, C.; Yamashita, H.; Anpo, M. Carbon 1995 33,3 .

(36) Toebes, M. L.; Bitter, J. H.; van Dillen, A. J.; de Jong, K. P. Catal. Today 2002, 76, 33

(37) Scholten, J. J. F.; Pijpers, A. P.; Hustings, A. M. L. Catal. Rev. Sci. Eng. 1985, 27, 151. 
(38) Gijzeman, O. L. J. Unpublished results.

(39) He, H.; Klinowski, J.; Fortser, M.; Lerf, A. Chem. Phys Lett. 1998 $287,53$.

(40) Toebes, M. L.; van Heeswijk, J. M. P.; Bitter, J. H.; van Dillen, A. J.; de Jong, K. P. Carbon 2004, 42, 307.

(41) Sawyer, D. T.; Gearge R. S.; Bagger, J. B. J. Am. Chem. Soc. 1959, $81,5893$.

(42) Bond, G. C.; Wells, P. B. Appl. Catal. 1985, 18, 225.

(43) Goquet, A.; Aouine, M.; Cadete Santos Aires, F. J.; De Mallmann, A.; Schweich, D.; Candy, J. P. J. Catal. 2002, 209, 135.

(44) Spieker, W. A.; Liu, J.; Miller, J. T.; Kropf, A. J.; Regalbuto, J. R. Appl. Catal., A 2002, 232, 219.

(45) Theodoridou, E.; Jannakoudakis, A. D.; Jannakoudakis, P. D. Pagalos, N.; Besenhard, J. O.; Donner, C. I.; Wicher, M. Electrochim. Acta 1993, 38, 793 .
(46) Santhanam, N.; Conforti, T. A.; Spieker, W.; Regalbuto, J. R. Catal. Today 1994, 21, 141

(47) Fletcher, J. M.; Jenkins, I. L.; Lever, F. M.; Martin, F. S.; Powell, A. R.; Todd, R. J. Inorg. Nucl. Chem. 1955, 1, 378.

(48) Boehm, H. P. Carbon 2002, 40, 145.

(49) Domingo-Garcia, M.; Lopez Garzon, F. J.; Perez-Mendoza, M. J. J. Colloid Interface Sci. 2002, 248, 116.

(50) Haydar, S.; Moreno-Castilla, C.; Ferro-Garcia, M. A.; CarrascoMarin, F.; Rivera-Utrilla, J.; Perrard, A.; Joly, J. P. Carbon 2000, 38, 1297. (51) Rosenfeld, J. M.; Murphy, C. B. Talanta 1967, 14, 91

(52) Asprey, S. P.; Wojciechowski, B. W.; Rice, N. M.; Dorcas, A. Chem. Eng. Sci. 1996, 51, 4681.

(53) Liu, W.; Lee, H. K. J. Chromatogr. A 1998, 805, 109.

(54) Ferreira, A. V.; van der Merwe, H. J.; Slippers, S. C. Small Ruminant Res. 1996, 22, 79. 